\title{
Tacinga inamoena vegetal drug characterization using phytochemistry, pharmacopoeial methods and thermoanalytical techniques
}

\author{
Joanda Paolla Raimundo e Silva ${ }^{1}$, Malu Maria Lucas dos Reis ${ }^{1}$, \\ Cleildo Pereira Santana ${ }^{1}$, Ana Cláudia Dantas de Medeiros ${ }^{1}$, \\ Harley da Silva Alves ${ }^{\circledR *}$
}

${ }^{1}$ Department of Pharmacy, Post-Graduation Program in Pharmaceutical Sciences, State University of Paraiba, Campina Grande, Paraiba, Brazil

\begin{abstract}
Tacinga inamoena (K. Schum.) N.P. Taylor \& Stuppy, also known as quipá, is a native cactus of the Caatinga used in traditional medicine to treat urethral infections and inflammation. This study aimed to determine the physicochemical characteristics of vegetal drug obtained from the roots of T. inamoena. Analytical techniques and phytochemical tests were used, such as thermal analysis, qualitative and semiquantitative determination of secondary metabolites and spectroscopy at the infrared region. The powder of the vegetal drug met the parameters established by the Brazilian Pharmacopoeia, except for compressibility, which was low. On the thermogravimetric curve, three events related to the mass loss were verified, which correlate with the vegetal drug quality control and play a part in their standardization. The qualitative screening suggested the presence of alkaloids, flavonoids and terpenes. The infrared spectrum reinforced the presence of hydroxyl, carbonyl, and ether groups. In the semiquantitative screening, a concentration for total polyphenols of $65 \mathrm{mg}$ equivalent to gallic acid $\mathrm{g}^{-1}$ to the crude ethanol extract (CEE) was obtained. On the correlation of flavonoid content to seasonality, a concentration was obtained of $3.3 \mathrm{mg}$ equivalent to quercetin $\mathrm{g}^{-1}$ to the $\mathrm{CEE}$ obtained during the drought period and of $10.6 \mathrm{mg}$ equivalent to quercetin $\mathrm{g}^{-1}$ to the $\mathrm{CCE}$ obtained during the rainy season. In T. inamoena, the presence of important classes of secondary metabolites, which are associated with the pharmacognostic characterization, aids the authentication and quality control of vegetal drugs of importance in traditional Brazilian medicine.
\end{abstract}

Keywords: Cactaceae. Quality control. Herbal medicine. Secondary metabolites. Thermogravimetry.

\section{INTRODUCTION}

Tacinga inamoena (K. Schum.) N.P. Taylor \& Stuppy is a cactus also known as quipá, cumbeba, or gogóia. It is a native of the northeast region in Brazil and is spread throughout almost all of the semiarid region. It is used in the countryside for animal feed and as a popular medicine to treat urethral diseases, asthma and inflammation, as well as to combat worms (Castro

*Correspondence: H. S. Alves, Laboratório de Fitoquímica, Departamento de Farmácia, Universidade Estadual da Paraíba, Rua Baraúnas, 351, Bodocongó, 58429-500 - Campina Grande, Paraíba, Brasil. Phone: +55 83 33153300 (Ext. 3516).E-mail: harley.alves@hotmail.com
\& Cavalcante, 2011; Zappi, Taylor, \& Machado, 2012; Menezes, Taylor, \& Loiola, 2013). In Brazil's semiarid areas, a growing interest has been observed in studies of the region's species (Arrais et al., 2014), particularly for their potentially abundant curative properties; yet there is been little study regarding their molecules' bioactive powers to this date (Arrais et al., 2014; Ribeiro et al., 2014).

Physicochemical analysis is the preliminary step for achieving a quality standard necessary for vegetal material and, thereby, assigning a high quality to new herbal medicines' constitutions (Souza-Moreira, Salgado, \& Pietro, 2010; Peña Muniz et al., 2015). 
The milling of the raw plant material is a critical step in obtaining vegetal drugs, extracts, and herbal medicines, and therefore, granulometry powder control is an important step of the production process (Correia et al., 2016). Among the analyses performed to ensure vegetal drugs' quality are quantitative and qualitative analyses of purity, integrity, and active contents (USP, 2012). Such analytical methods, especially thermal analysis (DSC, DTA, and TG), are the best methods for studying drugs, extracts, and active substances derived from medicinal plants (Fernandes et al., 2016). Only a small number of studies have been conducted on the thermal characterization of these products, although these active ingredients have been in use for a long time for the production of herbal medicines (CartaxoFurtado et al., 2017).

Thus, the aim of this study was to determine the physicochemical and phytochemical characteristics of the vegetal drug obtained from the roots of $T$. inamoena.

\section{MATERIAL AND METHODS}

\section{Raw material and extract production}

Roots from $T$. inamoena were collected at the Canhoto Farm (latitude: $07^{\circ} 28^{\prime} 47^{\prime \prime}$, longitude: $38^{\circ} 02^{\prime}$ 32"), in Nova Olinda, Paraíba. The specimen voucher from the vegetal material was deposited at the Herbarium of the Federal University of Paraíba under protocol JPB 61263. The plant material was dried in a circulating air oven at $40 \pm 1{ }^{\circ} \mathrm{C}$ and pulverized in a knife miller with a particle size of 10 mesh.

The dry and pulverized material (322 g) was exhaustively extracted with ethanol (EtOH) and concentrated under vacuum conditions at an average temperature of $50{ }^{\circ} \mathrm{C}$, yielding $23 \mathrm{~g}$ of the crude ethanol extract (CEE).

\section{Physicochemical characterization}

\section{Granulometry}

The granulometry test followed the methodology described in the Brazilian Pharmacopoeia (Brazil, 2010). The procedure used 25 grams of powder from T. inamoema roots, submitted to a series of sieves with different-sized mesh openings $(710,355,180,150,75$, and $38 \mu \mathrm{m}$ ) under vibration for 20 minutes. The particle sizes were analyzed in triplicate and evaluated through the powder-retention percentage quantification in each sieve according to equation (1):

$\%$ retained by sieve $=P_{1} / P_{2} \times 100$

where,

$\mathrm{P}_{1}=$ weight of the sample retained by each sieve (in grams)

$\mathrm{P}_{2}=$ sum of the weight retained in each sieve and in the collector (in grams).

\section{Density determination}

For density determination, 10 grams of powder from $T$. inamoema were packed in a graduated cylinder of $50 \mathrm{~mL}$ (Lagos, Pereira, \& Bertol, 2012), with the measured initial volume, and the apparent density (ad) was calculated (equation 2). The compacted density (cd) (equation 3) was measured after the graduated cylinder was subjected to successive beat movements vertically at a height of $20 \mathrm{~cm}$ up to 500 times. From the apparent and compacted densities, the Hausner Factor (HF) and the compressibility index (CI) were determined (USP, 2007), according to equations (4) and (5), respectively.

$$
\begin{aligned}
& a d=\frac{\mathrm{Am}}{A v} \\
& c d=\frac{\mathrm{Am}}{C v} \\
& \mathrm{HF}=\frac{c d}{a d} \\
& \mathrm{CI}=\frac{c d-a d}{a d}
\end{aligned}
$$

where,

Am $=$ apparent mass,

$A v=$ apparent volume,

$\mathrm{Cv}=$ compacted volume.

\section{Ash contents}

A total of 9 grams of root powder obtained from T. inamoema was spread in equal proportions in three porcelain containers previously calcined, cooled, and weighed. The samples were carbonized in a muffle 
furnace and incinerated at $450{ }^{\circ} \mathrm{C}$ for 2 hours. After cooling in desiccators, the samples were weighed using an analytical balance, and the procedure was repeated until a constant weight was obtained (Brazil, 2010). The ash percentage, obtained in triplicate, was calculated in relation to the dried powder, according to equation 6 :

$\%$ Ashes $=\frac{\mathrm{P}_{2}-\mathrm{P}_{1}}{P_{3}} \times 100$

where,

$\mathrm{P}_{1}=$ crucible weight after calcination and cooling

$\mathrm{P}_{2}=$ crucible weight of the sample after calcination and cooling

$\mathrm{P}_{3}=$ initial weight of the sample

\section{Moisture content determination}

The test was conducted in triplicate and the obtained values were evaluated in terms of weight percentage of the sample quantity (equation 7), according to Brazil (2010):

$\%$ loss $=\frac{\mathrm{P}_{\mathrm{u}}-\mathrm{P}_{\mathrm{s}}}{P_{a}} \times 100$

$\mathrm{P}_{\mathrm{a}}=$ sample weight $(\mathrm{g})$.

$\mathrm{P}_{\mathrm{u}}=$ weight of the filter containing the sample before desiccation $(\mathrm{g})$.

$\mathrm{P}_{\mathrm{s}}=$ weight of the filter containing the sample after desiccation $(\mathrm{g})$.

\section{Phytochemical prospecting}

The CEE was subjected to phytochemical screening (Table II) following the methodologies described by Matos (2009).

\section{Quantification of polyphenols}

The total polyphenol content of plant extracts was measured by the Folin-Ciocalteu reagent method, as described by Chaves et al. (2013). The extracts were dissolved in distilled water to obtain a final concentration of $200 \mu \mathrm{g} \mathrm{mL}^{-1}$. From each solution, a $1 \mathrm{~mL}$ aliquot was added to $1 \mathrm{~mL}$ of $1 \mathrm{~mol} \mathrm{~L}^{-1}$ Folin-Ciocalteu reagent (SigmaAldrich $($ ). This mixture remained undisturbed for $2 \mathrm{~min}$ before the addition of $2 \mathrm{~mL}$ of $20 \%$ (w:v) $\mathrm{Na}_{2} \mathrm{CO}_{3}$ solution and then left undisturbed for $10 \mathrm{~min}$. Thereafter, the reading was performed using a Shimadzu ${ }^{\circledR}$ spectrophotometer at $757 \mathrm{~nm}$. The calibration curve was obtained with a solution of gallic acid (Sigma-Aldrich ${ }^{\circledR}$ ) from which dilutions were made at concentrations between 1 and $40 \mu \mathrm{gLL}^{-1}$. The test was conducted in triplicate.

\section{Quantification of flavonoids}

The total flavonoid content was determined by the $\mathrm{AlCl}_{3}$ method (Meda et al., 2005; Chaves et al., 2016). The extracts were diluted with methanol (1000 $\mu \mathrm{g} \mathrm{mL}-1)$. The same volume of $2 \%(\mathrm{w}: \mathrm{v}) \mathrm{AlCl}_{3}$ solution in methanol was added to each test solution. This mixture remained undisturbed for $10 \mathrm{~min}$ before the UV spectrophotometric reading at $415 \mathrm{~nm}$ wavelength. The total flavonoids was determined by the calibration curve using quercetin (Sigma-Aldrich $®$ ) as a standard at concentrations between 2 and $30 \mu \mathrm{g} \mathrm{mL}^{-1}$. The test was conducted in triplicate.

\section{Quantification of tannins}

The content of condensed tannins was verified using the method described by Makkar and Becker (1993) and Chaves et al., (2016), wherein $0.25 \mathrm{~mL}$ of the sample $\left(1000 \mu \mathrm{g} \mathrm{mL}^{-1}\right)$ was added to $1.5 \mathrm{~mL}$ vanillin (Sigma-Aldrich $\left.{ }^{\circledR}\right)$ dissolved in methanol $(4 \%$ w:v) and, subsequently, in $0.75 \mathrm{~mL}$ of concentrated $\mathrm{HCl}(37 \%)$. After the $\mathrm{HCl}$ addition, the contents of the tube were shaken in a water bath at $30{ }^{\circ} \mathrm{C}$ before being read on a spectrophotometer at a $500 \mathrm{~nm}$ wavelength. Catechin (Sigma-Aldrich ${ }^{\circledR}$ ) was used as a standard at concentrations between 10 and $100 \mu \mathrm{g} \mathrm{mL}{ }^{-1}$. The test was conducted in triplicate.

\section{Analytical techniques}

\section{Differential Thermal Analysis (DTA)}

The DTA curves were obtained with a Q600 SDT (TA Instruments ${ }^{\circledR}$ ) simultaneous analyzer using aluminum crucibles containing $2.0 \pm 0.1 \mathrm{mg}$ of the sample under a nitrogen atmosphere (flow of $50.0 \mathrm{~mL}$ $\left.\mathrm{min}^{-1}\right)$. The experiments were conducted between temperatures of 30 and $400{ }^{\circ} \mathrm{C} \mathrm{min}^{-1}$ by heating at $10{ }^{\circ} \mathrm{C}$ $\mathrm{min}^{-1}$. Indium $\left(\mathrm{mp} 156.6^{\circ} \mathrm{C}\right.$ ) was used as the standard for equipment calibration. 


\section{Thermogravimetry $(T G)$}

The TG curves were obtained using a simultaneous thermal analyzer, model Q600 (TA Instruments $\left.{ }^{\circledR}\right)$. The mass of the samples was $8.00 \pm 0.05 \mathrm{mg}$, weighed on an analytical balance and packed in aluminum crucibles. The sample was uniformly distributed on the bottom of the crucible. The experiments were programmed at a temperature range from 30 to $900{ }^{\circ} \mathrm{C}$ under a dynamic atmosphere of nitrogen $\left(50 \mathrm{~mL} \mathrm{~min}{ }^{-1}\right)$ using a heating rate of $10^{\circ} \mathrm{C} \mathrm{min}^{-1}$.

\section{Fourier-transform infrared spectroscopy (FT-IR)}

FT-IR spectra of vegetal extracts were recorded on a Perkin-Elmer model 1600 apparatus using $\mathrm{KBr}$ stressed discs in the range of 4000-500 $\mathrm{cm}^{-1}$.

\section{RESULTS AND DISCUSSION}

According to the pharmacopoeia, the powder resulting from the vegetal drug was classified as semi-thin. The granulometric distribution of vegetal drugs represents a parameter for the choice of the extractive process and, consequently, obtaining the chemical constituents of pharmaceutical interest, as well as the aspects inherent to the pulverized vegetal material, represent a critical stage in the production of phytotherapeutic drugs (Alves et al., 2010).

The average of the obtained value of the matter lost by desiccation in $T$. inamoena was $10.11 \%$, according the established limits from the Brazilian Pharmacopoeia this result that can vary from 8 to $14 \%$ (Brazil, 2010). values within acceptable limits implies a positive results in regard to microbiological control and hydrolysis reactions, because both cause chemical deterioration (Couto et al., 2009).

The Hausner Factor was calculated based on the brute and compaction density and corresponded to 1.43 (Table I), classifying the vegetal material as cohesive. Thereby, the powder of the roots obtained from $T$. inamoena presented poor flow properties, as corroborated by the to the compressibility index (43.47\%), because IC values $>38 \%$, are considered very flow poor. Consequently, this powder will present difficulties on the compression process, a relevant point of the medicine's production network in a solid form (USP, 2007; Garcia, Pereira, \& Dias, 2012; Lagos, Pereira, \& Bertol, 2012).
TABLE I - Physicochemical properties of the vegetal drug from T. inamoena

\begin{tabular}{lc}
\hline Physicochemical properties & Values \\
\hline Compaction density $\left(\mathrm{g} \mathrm{mL}^{-1}\right)$ & 0.33 \\
Brute density $\left(\mathrm{g} \mathrm{mL}^{-1}\right)$ & 0.23 \\
Compressibility $(\mathrm{mL})$ & 10.5 \\
Compressibility index $(\%)$ & 43.47 \\
Hausner ratio & 1.43 \\
Ashes content $(\%)$ & 11.06 \\
Desiccation loss $(\%)$ & 10.11 \\
\hline
\end{tabular}

For the total amount of ash test, a percentage of $11.06 \%$ of inorganic matter was observed, below $14 \%$, according to the established limits from the Brazilian Pharmacopoeia (Brazil, 2010), thereby indicating that samples did not contain excess soil and/or sand.

In the qualitative screening, it was possible to detect the presence of nitrogenous composed as alkaloids, beyond steroids/terpenes and flavonoids (Table II). The presence of those compounds provides a larger valuation of the vegetal species due to the therapeutic potentiality related to those metabolites, among other activities (Souza et al., 2014; Zhao et al., 2016; Ding et al., 2017).

TABLE II - Qualitative screening and content metabolites present in the CEE from $T$. inamoena

Qualitative screening Results

Bouchardat +

Mayer

Dragendorff

$+$

Catechins

Steroids/Terpens $+$ 
TABLE II - Qualitative screening and content metabolites present in the CEE from T. inamoena

\begin{tabular}{lc}
\hline Qualitative screening & Results \\
\hline Tannin & - \\
Flavonoids & + \\
Polisaccharides & - \\
Saponines & - \\
\hline Phenols compounds content & Results \\
Flavonoids (september) & $3.3 \mathrm{mg} \mathrm{g}^{-1}$ \\
Flavonoids (february) & $10.6 \mathrm{mg} \mathrm{g}^{-1}$ \\
Poliphenols (september) & $65 \mathrm{mg} \mathrm{g}^{-1}$ \\
\hline
\end{tabular}

$(-)$ negative; $(+)$ positive

The total polyphenol analyses revealed the presence of $65 \mathrm{mg}$ equivalent to gallic acid $\mathrm{g}^{-1}$ to the CEE, without a quantified value of tannins (Table II). Among the phenolic compounds belonging to the secondary metabolism of the vegetal matter are found structures such as phenolic acids, flavonoids, coumarins, water-soluble pigments, tannins, alkaloids, and conjugated terpenes that are related, mainly, to the protection of the vegetal species related to its resistance to microorganisms and pests (Rocha et al., 2011).

The flavonoid content presents a concentration of $3.3 \mathrm{mg}$ equivalent quercetin $\mathrm{g}^{-1}$ to the CEE, corresponding to a drought period in the Paraíba (September 2014), while the values for the rainy season (February 2014) provided $10.6 \mathrm{mg}$ equivalent quercetin $\mathrm{g}^{-1}$ to the CEE (Table II). Given this scenario, a greater variation of flavonoids was understood to be aligned with a higher rainfall index. It can be inferred that the higher amount of water availability predisposed the growth of flavonoid production, possibly because in this period, the xerophytes species demonstrate higher metabolic production. Budding, flowering, and fruiting occur during this stage, while in the drought period, the plant tends to discontinue several functions in order to guarantee the species' survival, conferring a level of tolerance to the plants related to water stress. This variation on the synthesis of secondary metabolites, affected by environmental conditions, represents a chemical interface between the plant and the surrounding ambient climate (Kutchan, 2001; Gobbo-Neto, Lopes, 2007; Santos, Reis, 2008; Chaves et al., 2013).

The TG curves demonstrated the occurrence of three events of mass loss (Figure 1, Table III). For the first, an endothermic stage was observed (Figure 1, Table IV), with a mass loss of $9.7 \%$. This event can be related to the vegetal drug's dehydration and to the evaporation of volatile constituents (Santos et al., 2011; Brandão et al., 2016).

For the second event, there was a loss equivalent to $47.16 \%$ of the material mass, a significant loss that can be attributed to the carbohydrates' thermal decomposition and other organic compounds present (Santos et al., 2011; Costa et al., 2013; Brandão et al., 2016). In the third and last event, the mass loss was equivalent to $32.34 \%$ between the temperatures of $359.03{ }^{\circ} \mathrm{C}$ and $532.49^{\circ} \mathrm{C}$. This final loss can be attrbuted to the burning of the remains of organic matter (Costa et al., 2013).

The events described by the TG curves can also be observed when analyzing the DTA curves (Figure 1, Table IV), which confirms the occurrence of the three events related to the mass loss, those events being important to the standard of the vegetal drugs obtained from the roots of $T$. inamoena.

On the IR (Figure 2) spectrum, it was possible to view a broad band with medium intensity in $3300 \mathrm{~cm}^{-1}$ characteristic of a hydroxyl grouping $(\mathrm{OH})$ and two bands with low intensity in 2900 and $2880 \mathrm{~cm}^{-1}$, indicative of methyl and methylene groups with hybridization $\mathrm{sp}^{3}$. A narrow band suggestive of carbonyl grouping can be observed at $1650 \mathrm{~cm}^{-1}$ and an intense band characteristic of CO grouping at $1000 \mathrm{~cm}^{-1}$ (Pavia et al., 2012). The indicative signals from those functional groups correlate with the phytochemical analysis, suggesting the presence of phenolic compounds.

The study indicates the presence of classes of metabolites with recognized health benefits, establishes a connection of flavonoid production associated with the medium in which $T$. inamoena is inserted, and determines parameters for the control of the quality of the vegetal drug. In these ways, it contributes to the knowledge of medicinal species and establishes data that may refer to the identity of the vegetal drug produced from $T$. inamoena. 


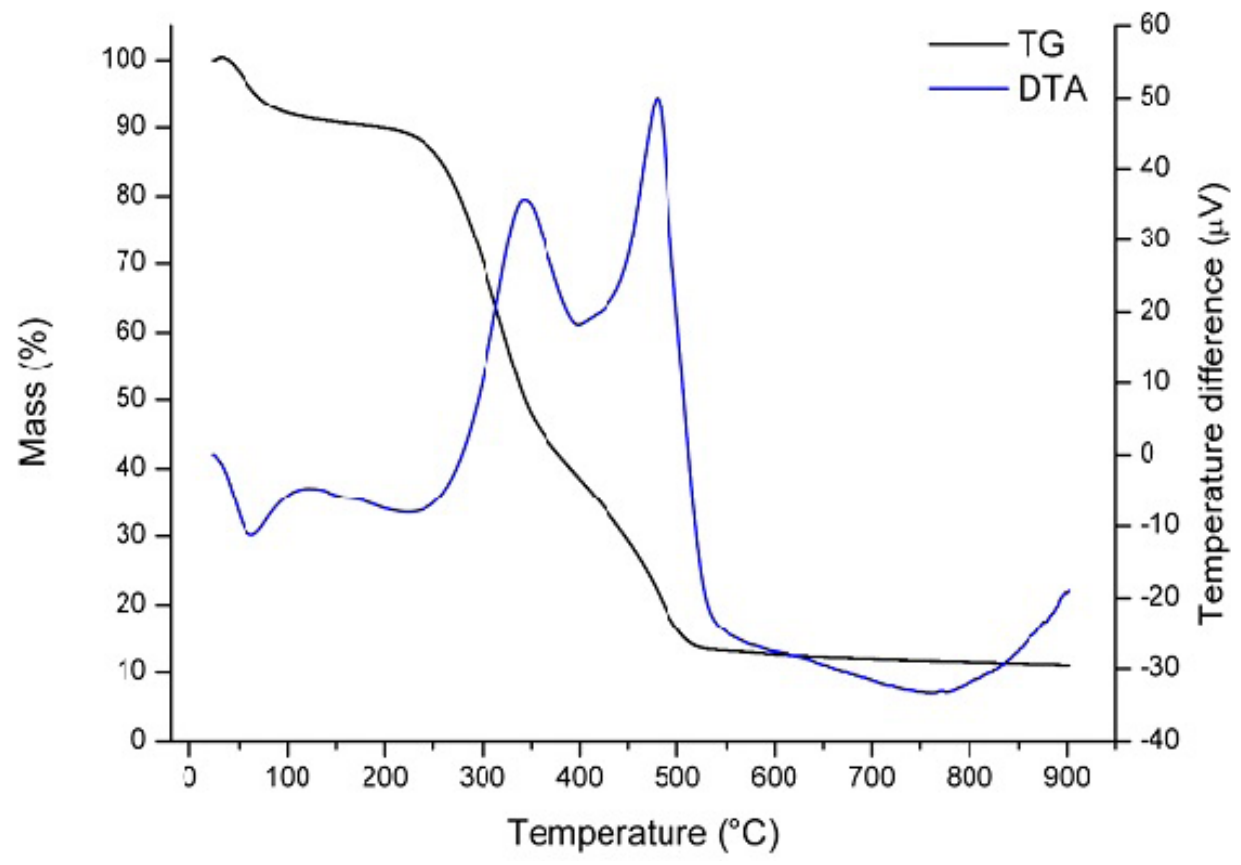

FIGURE 1 - Thermogravimetric curve and differential thermal analysis of vegetal drug from T. inamoema

TABLE III - Data of thermogravimetric curve of the roots from $T$. inamoema, with their respective losses of mass, in each temperature range $\left({ }^{\circ} \mathrm{C}\right)$

\begin{tabular}{lccc}
\hline Events & Onset - Endset $\left({ }^{\circ} \mathbf{C}\right)$ & Loss of mass $(\%)$ & Initial mass \\
\hline $1^{\text {a }}$ stage & $33.59-160.58$ & 9.7 & $7.11 \mathrm{mg}$ \\
$2^{\mathrm{a}}$ stage & $203.78-359.03$ & 47.16 & Residue \\
$3^{\mathrm{a}}$ stage & $359.03-532.49$ & 32.31 & $10.97 \%$ \\
\hline
\end{tabular}

TABLE IV - Data of differential thermal analysis of the roots from T. inamoema

\begin{tabular}{lccc}
\hline Events & Onset - Endset $\left({ }^{\circ} \mathbf{C}\right)$ & $\Delta \mathbf{H}\left(\mathbf{J ~ g}^{-1}\right)$ & Peak $\left({ }^{\circ} \mathbf{C}\right)$ \\
\hline $1^{\mathrm{a}}$ stage & $25.32-111.27$ & -530.59 & 63.22 \\
$2^{\mathrm{a}}$ stage & $229.89-400.55$ & 2440.72 & 342.83 \\
$3^{\mathrm{a}}$ stage & $400.16-539.46$ & 2884.22 & 473.06 \\
\hline
\end{tabular}




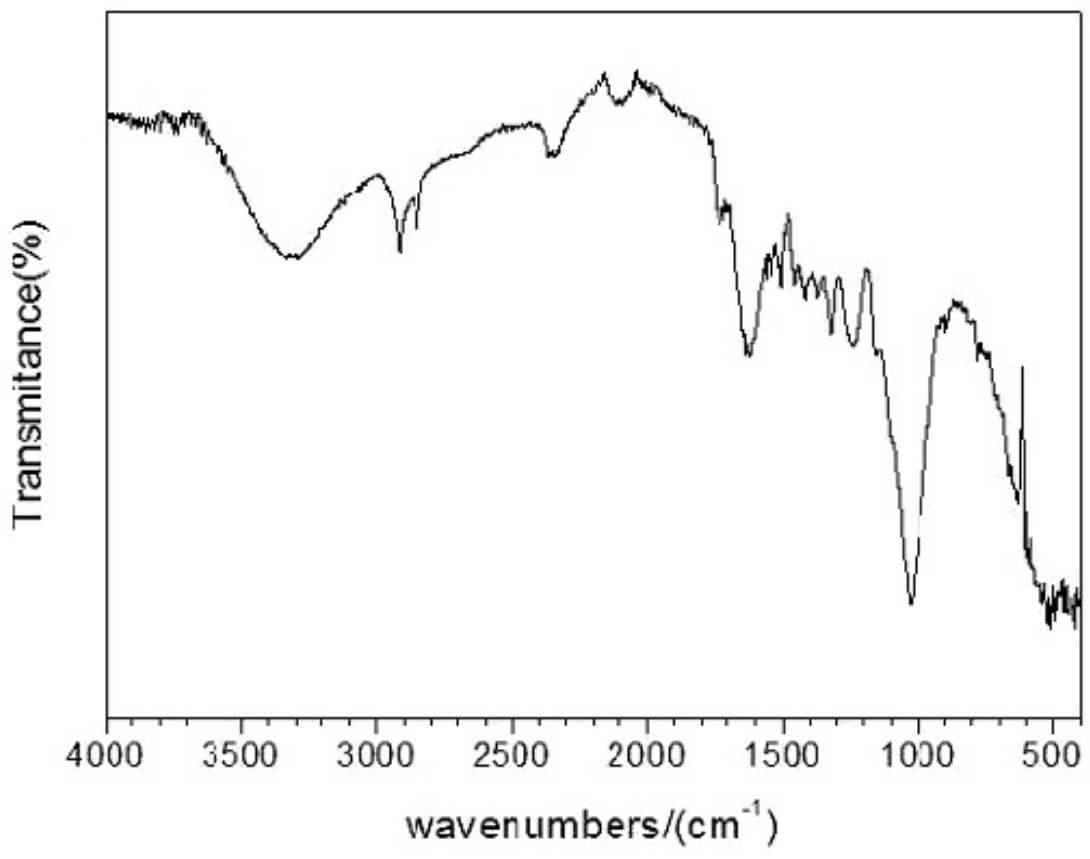

FIGURE 2 - Infrared spectrum of the vegetal drug from T. inamoema.

\section{REFERENCES}

Alves MSM, Mendes PC, Vieira JGM, Ozela EF, Barbosa LR, Silva Júnior JC. Pharmacognostic analysis of Arrabidaea chica (Humb. \& Bonpl.) B. Verlt. Leaves, Bignoniaceae. Rev Bras Farmacogn. 2010;20(2):215-221.

Arrais LG, Lyra HFS, Batista DCA, Coutinho FN, Saraiva AM, Pereira RCA, et al. Antimicrobial activity of methanol extracts of root, stem and leaves of Croton pulegioides Baill. Rev Bras Pl Med. 2014;16(2):316-322.

Brandão DO, Guimarães GP, Santos RL, Ramos Junior FJL, Silva KMA, Souza FS, et al. Model analytical development for physical, chemical, and biological characterization of Momordica charantia vegetable drug. J Anal Methods Chem. 2016;2016:7528297.

Brazil. Brazilian Pharmacopoeia. $5^{\circ}$ ed. Brasília: National Health Surveillance Agency - ANVISA; 2010.

Cartaxo-Furtado NAO, Castilho ARF, Freires IA, Santana CP, Sampaio TO, Xavier MA; et al. Physicochemical characterization of a new raw material obtained from leaves of Syzygium cumini (L.) Skeel (Myrtaceae). J Therm Anal Calorim. 2017;127(2):1137-41.
Castro A, Cavalcante A. Flowers of Caatinga. Campina Grande: Instituto Nacional do Semiárido - INSA; 2011.

Chaves TP, Santana CP, Véras JG, Brandão DO, Felismino $\mathrm{DC}$, Medeiros ACD, et al. Seasonal variation in the production of secondary metabolites and antimicrobial activity of two plant species used in Brazilian traditional medicine. Afr J Biotechnol. 2013;12(8):847-853.

Chaves TP, Fernandes FHA, Santana CP, Santos JS, Medeiros FD, Felismino DC, et al. Evaluation of the interaction between the Poincianella pyramidalis (Tul.) LP Queiroz extract and antimicrobials using biological and analytical models. Plos One. 2016;11(5):e0155332.

Correia LP, Santana CP, Medeiros ACD, Macêdo RO. Sideroxylon obtusifolium herbal medicine characterization using pyrolysis GC/MS, SEM and different thermoanalytical techniques. J Therm Anal Calorim. 2016;123(2):993-1001.

Costa RS, Negrão CAB, Camelo SRP, Ribeiro-Costa RM, Barbosa WLR, Costa CEF, et al. Investigation of thermal behavior of Heliotropium indicum L. lyophilized extract by TG and DSC. J Therm Anal Calorim. 2013;111(3): 1959-1964.

Couto RO, Valgas AB, Bara MTF, Paula JR. Physicochemical characterization of the powder from leaf of Eugenia dysenterica DC. (Myrtaceae). Rev Eletr Farm. 2009;6(3):59-69. 
Joanda Paolla Raimundo e Silva, Malu Maria Lucas dos Reis, Cleildo Pereira Santana, Ana Cláudia Dantas de Medeiros, Harley da Silva Alves

Ding Y, Qu D, Zhu J, Cang XX, Kou ZN, Xiao W, et al. Phytochemical and biological investigations of Amaryllidaceae alkaloids: a review. J Asian Nat Prod Res. 2017;19(1):53-100.

Fernandes, FHA, Almeida VE, Medeiros FD, Silva PCD, Simões MODS, Veras JG, et al. Evaluation of compatibility between Schinopsis brasiliensis Engler extract and pharmaceutical excipients using analytical techniques associated with chemometric tools. J Therm Anal Calorim. 2016;123(3):2531-2542.

Garcia AQR, Pereira TCB, Dias ILT. Study of the flow in the development of acetaminophen powder dispensed into sachet. Rev Bras Farm. 2012;93(4):469-475.

Gobbo-Neto L, Lopes NP. Medicinal plants: factors of influence on the content of secondary metabolites. Quim Nova. 2007;30(2):374-381.

Kutchan TM. Ecological arsenal and developmental dispatcher. The paradigm of secondary metabolism. Plant Physiol. 2001;125(1):58-60.

Lagos VV, Pereira RN, Bertol CD. Propriedades micromeríticas e análise físico-química de matérias-primas de alopurinol. Rev Ciênc Farm Básica Apl. 2012;33(3):385-393.

Makkar HPS, Becker K. Vanillin-HCl method for condensed tannins: effect of organic solvents used for extraction of tannins. J Chem Ecol. 1993;19(4):613-621.

Matos FJA. Introdução à Fitoquímica Experimental. 3rd ed. Fortaleza: Edições UFC; 2009.

Meda A, Lamien CE, Romito M, Millogo J, Nacoulma, OG. Determination of the total phenolic, flavonoid and proline contents in Burkina Fasan honey, as well as their radical scavenging activity. Food Chem. 2005;91(3):571-577.

Menezes MOT, Taylor PG, Loiola MIB. Flora do Ceará, Brasil: Cactaceae. Rodriguésia. 2013;64(4):757-74.

Pavia DL, Lampman GM, Riz GS, Vyvyan JR. Introdução à espectroscopia. 4th ed. São Paulo: Cengage Learning; 2012.

Peña Muniz MA, Ferreira dos Santos MN, Costa CEF, Morais L. Lamarão MLN, Ribeiro-Costa RM, et al. Caracterização físico-química, composição de ácidos graxos e análise térmica do óleo de Bertholletia excelsa HBK. Pharmacogn Mag. 2015;11(41):147-151.

Ribeiro DA, Macêdo DG, Oliveira LGS, Saraiva ME, Oliveira SF, Souza MMA, et al. Potencial terapêutico e uso de plantas medicinais em uma área de Caatinga no estado do Ceará, Nordeste do Brasil. Rev Bras Plantas Med. 2014;16(4):912-930.

Rocha WS, Lopes RM, Silva DB, Vieira RF, Silva JP, Agostini-Costa TS. Total phenolic compounds and condensed tannins in native fruits of the cerrado. Rev Bras Frutic. 2011;33(4):1215-1221.

Santos LA, Reis VMA. Nodule Formation in Legumes. Seropédica-RJ: Embrapa Agrobiologia. 2008;251:14.

Santos ML, Lima OJ, Nassar EJ, Ciuffi KJ, Calefi P. Estudo das condições de estocagem do bagaço de cana-de-açúcar por análise térmica. Quím Nova. 2011;34(3):507-511.

Souza-Moreira TM, Salgado HRN, Pietro RCLRO. Brasil no contexto de controle de qualidade de plantas medicinais. Rev Bras Farmacogn. 2010;20(3):435-440.

Souza MT, Almeida JR, Souza Araujo AA, Duarte MC, Gelain DP, Moreira, JC, et al. Structure-activity relationship of terpenes with anti-inflammatory profile - a systematic review. Basic Clin Pharmacol Toxicol. 2014;115(3):244-256.

USP. United States Pharmacopoeia 30 \& National Formulary 25. Rockville: United States Pharmacopeial Convention; 2007.

USP. The United States Pharmacopoeia. $36^{\text {th }}$ ed. Rockville: The United States Pharmacopeial Convention; 2012.

Zappi D, Taylor N, Machado M. Cactaceae in Lista de Espécies da Flora do Brasil: Jardim Botânico do Rio de Janeiro. 2012. [cited 2017 Jun 14]. Available from: http:// floradobrasil.jbrj.gov.br/2012/FB000070

Zhao, Yu, Kun Zhao, Kai Jiang, Shanshan Tao, Yunxia Li, Wenwen Chen, et al. A review of flavonoids from cassia species and their biological activity. Curr Pharm Biotechnol. 2016;17(13):1134-1146.

Received for publication on $09^{\text {th }}$ June 2018 Accepted for publication on $21^{\text {st }}$ January 2019 